\title{
Construction and Practice of Multifunctional Training Teaching System for Rural Power Specialty
}

\author{
Lili Gao ${ }^{1, a}$ and Xingru Lu, b \\ ${ }^{1}$ School of Engineering and Technology, Jilin Agricultural University, Changchun, China \\ a568492564@qq.com, b1029645185@qq.com
}

Keywords: Training teaching system; Rural power specialty; Teaching content; Teaching method

engineer cultivation, and proposes multifunctional training teaching system based on agricultural modernization. To the problems of training teaching, multifunctional training teaching system for rural power specialty surrounds guiding thought of the multiple dimensions of training teaching objectives, the relevancy of training teaching contents, the diversification of training teaching methods and the gradualness of training teaching objectives, constructs from the two respects of training teaching content and training teaching method, and improves the cultivation of students' practical ability, innovative ability, learning ability, team spirit and engineering thinking.

\section{Introduction}

Training teaching, as an important part of practical teaching, have a key role in cultivating highquality technical talents with professional applying and Innovative ability[1]. In recent years, through the exploration and adjustment of the goal of talents cultivation in domestic agricultural universities, the training mode of agricultural engineering technical talents has got a fast development, but the training teaching system is not mature and perfect. Electrical information specialty, as the new major of agricultural universities, whose goal of talent cultivation is trite, whose training isn't also a system, whose training projects are no relationship, whose practicing base is not stable, which fails to provide good practicing platform for students, which cultivates agricultural engineering technical talents who could not satisfied requirement of the social development and the market economy, which restricts the development of agricultural modernization[2,3]. Therefore, combining the characteristics of profession and the social requirement, this article explores multifunctional training teaching system which is of great significance based on agricultural modernization by studying training patterns on cultivation of practical technical talent of rural power specialty.

\section{The Guiding Ideology for the Construction of Multifunctional Training Teaching System}

The guiding ideology for the construction of multifunctional training teaching system means it play a science guiding role on the cultivation of students' practical technical ability during the process of the training. It should show the effectiveness of translating students' knowledge into ability to ensure to enhance students' chances of operating practically, inspire students' interest in study, exercise students' technical ability, strengthen students to construct their knowledge actively and enhance students' comprehensive quality which is from simplest to more complex and gradual guidance by training teacher during the training teaching[4]. To a application-undergraduate talent, neither the learning of speculative knowledge nor the learning of application technology can be abandoned[5]. Therefore, in the construction of training teaching system, only by changing design pattern of training teaching system to arouse enthusiasm of students to think positively and actively that theoretical knowledge should be in harmony with practical operation by students who get promotion of comprehensive abilities[6].

The Multiple Dimensions of Training Teaching Objectives. The multiple dimensions of training teaching objectives is training must not only promote the learning of theoretical knowledge and the promotion of practical skill, but also promote the cultivation of the team spirit, innovation ability, learning ability and attitude to learning and so on. So, the multiple dimensions of training teaching objectives should be considered in the whole process of students' training, which is not 
restricted to the process of training teaching activities and also include students' learning process about training project before and after training. Training teaching focuses on of dynamic learning styles which are inseparable from teachers' guidance and students' participation. To ensure efficiency of training teaching process, concerning teaching objectives related to various stage of training, relying mainly on cultivating practical skills while making talents improving education quality as a subsidiary, making a point of designing projects of training teaching, transiting from knowledge externalization to internalization and development of skills and qualities.

The Relevancy of Training Teaching Contents. The goal of talent cultivation of rural power specialty not only have practical abilities but also have the capabilities of solving practical problems to determine composition of the range of students' knowledge. Training teaching should make a properly training contents according to students' knowledge structure at different stages and the corresponding professional courses; in the meantime training contents joint practical knowledge and speculative knowledge; different phases and different levels of training contents are also relation one another. So the design of training projects must take quality into consideration the relevancy of all training links which will enable student to obtain the opportunity of relating different aspects of learning and making comprehensive exercise of technology.

The Diversification of Training Teaching Methods. Training teaching of higher learning institutions at the present stage relies on teachers' presentation, teaching methods is single, these overlooked student's dominant and initiative role. Training teaching are still teacher's heading position, students complete teachers' requirements step-by-step who haven't the process of digestion and comprehending knowledge and whose capabilities of solving practical problems don't really get on exercise. The diversification of teaching methods not only interpret teachers' aim of asking and resolving, but also promotes the students' desire of exploring knowledge. The diversification of learning methods means students' activities of independent about understand, analysis, discussion, try, authentication, implement and repeated improvements of the projects during the training process. Through one's own efforts who masters of knowledge and ability is substantial yet profound. The diversification of training teaching methods can promote the improvement of students' integration capability.

The Gradualness of Training Teaching Objectives. The gradualness of training teaching objectives is not only embodied on step by step training teaching units, but also on step by step capability and quality. The acquisition of individual knowledge is learner-centered which is formed through experience, introspect, construct, repeated practice and accumulation of experience. Therefore, talent training is not an overnight thing and has to follow certain rules. Design the content of the training projects gradually and from simple to complex in line with development of students' knowledge and ability, then continuously add relevant training projects according to the effects of students' practice, again through training for mastering of knowledge and ability. It is an interactive process to study activities, the course of training can not be separated from guidance of teachers, to achieve training of high quality would orderly and gradually ask questions and enlighten students on thinking and summarizing, only in this way can we reach the goal of talents training.

\section{The Design and Construction of Multifunctional Training Teaching System}

Training Teaching Contents. Training teaching contents are composed primarily of the four units of the basic quality training, the professional skills training, the comprehensive skills training and the innovative practice training. The design of four training units gradually improved from arrives simply complex and from easy to difficult by function. Each training units consists of several progressive training teaching.

1) The basic quality training is mainly to freshmen and includes information inquiry, the use of instrument, the recognition of components, the operations of tools and the assessment of safety regulations. This section sets more training projects, students choose one of which on the basis of their own special interests and finish teachers' requirements on training projects through the teacher explains and independent learning. The freshmen are used to the study methods of senior and contact less and less in electricity practical operation. Cognitive training is the most basic, through simple 
training projects can increase the sense of the students' accomplishment of study, cultivate students' professional interests, expand the professional knowledge and strengthen enthusiasm of training for students.

2) Professional skills training is mainly to sophomores, which mainly combined with training projects of the specialized course design and includes circuit design, circuit simulation, assembled and adjusted, the welding circuit. It is the key stage of training students' professional skills and affects practice effect of sequence training units at the same time; it is more focused on demonstrating ability to analyze and comprehend, handling ability and attitude for students.

3) Comprehensive skills training is mainly to juniors and includes the practice in the campus and enterprise practice outside the campus. On the base of the preliminary stage of the training, it deepens the difficulty of the training and increases the writing, testing and optimization of the programs, data analysis, improvement circuit, industrial production and automatic controlling of the equip. Juniors already have relative theory of the profession and practical skills under the experience of freshmen and sophomores, so training projects are no longer simpler circuit design and equipment debugging but simulate or practical experience to enterprise productive task in this phase. Students integrating their knowledge and strengthen their own comprehensive qualities in the systematic task. This part focuses on developing the students' ability to think actively and solve problems.

4) Innovative practice training is mainly to juniors and seniors having a genuine interest and high professional capability, mainly combines competitive events of the subject and the research program of teachers, cultivates students' creativeness and engineering thinking. In addition, every student of senior will accomplishing their graduate design in the campus training center for six months or so, that will be the last known ascension on creativity ability and comprehensive quality of the students.

According to characters and the skill required of each unit in the training teaching system, build diagrams of training teaching contents for rural power specialty, as shown in figure1. At present, the four training units of the rural power specialty contain 167 training projects which include 13 the basic quality training units, 44 professional skills training units, 78 comprehensive skills training units and 32 innovative practice training units. Four training units are interrelated and dispensable. With rise in hierarchy, the proportion of the teachers' participation is less and less and the proportion of the students' participation is more and more. On the setting of Training projects, every training unit must have training requirements that match talents cultivation plan on the setting of training projects.

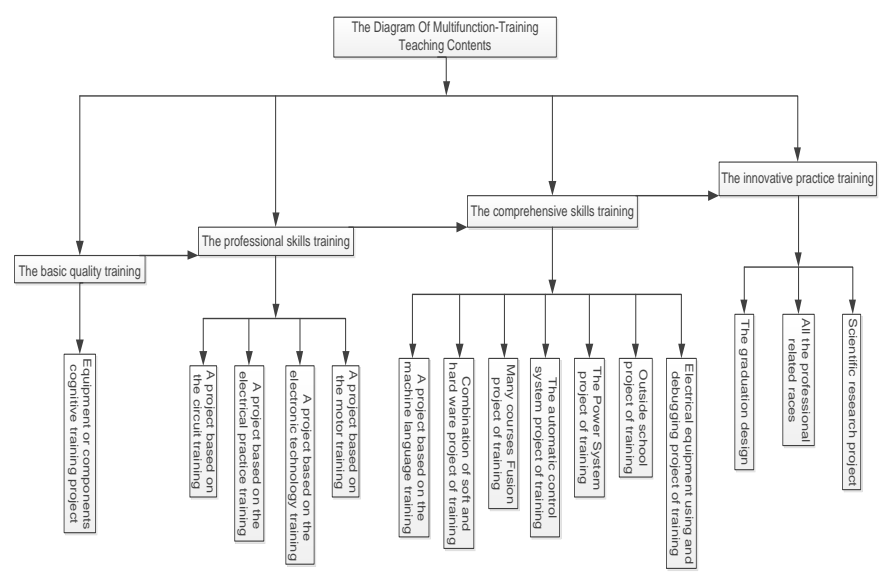

Figure 1. Finite The Diagram of Multifunctional Training Teaching Contents

Training teaching methods. The rural power specialty is a practical major, good practice teaching methods not only form an incentive for students to practice actively but also enhance students' practical ability and innovative thinking.

1) Teaching methods can adopt detail teaching method as well as example teaching method and objective teaching method at the stage of basic quality training. Detail teaching method is the teacher explains the basic knowledge, the operation rules as well as test methods and training procedures and so on. Example teaching method refers to teachers' operation as well as instruction 
and guidance to training projects until every student's operation is accurate and makes sure student have a solid basic operation. Objective teaching method is that teacher provides several training topic, students can choose a topic freely according to their interest and then finish their own topics required by training independently.

2) Teaching method can adopt question teaching method as well as elicitation teaching method and structural teaching method at the stage of professional skills training. Question teaching method is the teacher puts forward some problems to the knowledge and the key of project, several students as a group design experiment plan themselves and then complete training project after teachers' inspection and guidance. Elicitation teaching method is the teacher guide the students how to design circuits, how would be and how to install, modify and debug, not only which reduces students dependence on teachers but also develops the students' ability to analyze and solve problems. Structural teaching method is the teacher divides the project into several parts and guide students to solve the difficult problem step by step, students make clear the analysis thought under teacher's guidance, learn to reduce a big problem into a small problem and connecting the knowledge with the ability.

3) Teaching method can adopt situation teaching approach as well as practical teaching approach and explore teaching approach at the stage of comprehensive skills training. Situation teaching approach is equipment and materials of the simulated production sites, which gives the students the full experience of every process from product design to manufacturing through teachers explaining of the object and practices. Practical teaching approach is to expose the student to the training base of the enterprise for production practice and to learn practical experiences from the old employees, to make up for lack of natural talent by hard work, which bring the talents closer to the enterprise, which allows students to understand a corporate culture and cultivates students' vocational quality for employment to improve personal abilities. Explore teaching approach summarizes representative technologies and difficulties during production of training in the past, designs the corresponding training projects, integrates multi-subject knowledge and makes a summary of memories and thinking in the past experience of production practice under the instruction of teachers, reviews the old.

4) Teaching method can adopt open teaching method and autonomous teaching methodat the stage of innovative practice training. Open teaching method is that laboratory is open, student will be with regard to the practice of their own topics of graduation thesis, teachers will only do the direction guidance. Autonomous teaching method is for the race and the research content, students organized divide the work and cooperate with each other, express their opinions, work together to complete project, if students run into problems, the teacher should give inspiration as well as encouragement and guidance, these will cultivate the students' innovation and integration capability.

\section{The Effect of Implementation of Training Teaching System}

Rural power specialty has carried on multifunctional training teaching system for about two years in applied in 2011rd to 2016rd, which has centered around plan of training talent of the specialty, bases on guiding thinking of training teaching system, centers on training teaching contents and training teaching methods. By the operation of two years, training effect has developed a lot before comparison.

Improving the Students' Comprehensive Qualities and Technical Ability. Multifunctional training teaching system covers professionals more than 570 person, the graduation design and defense effect of two years' graduates have showed an obvious increase under the goal of cultivating talents of training system. Students' enthusiasm for participation and study runs high in practice of multifunctional training teaching system, who repeatedly participate electronic designing competition in province and nationwide, the challenge of automation and intelligent car competition, etc. Students win two national third prize and four province first prize and three province second prize. All the feedback from employers is that student's ability have improved when compared to those of former students and companies' willingness to hire have increased. These indirectly reflect that the new training teaching system has enhanced students' quality and ability. 
Improving Teachers' Ability. The formulation and implementation of multifunctional training teaching system not only help students, but also help teachers. Because of real-time updates on training projects, teachers do some research on frontier technology and then apply for on-campus and province and national science projects which are totally 9, publish more than ten research articles of EI index searching and Chinese core journal.

\section{Conclusions and Analyses}

The establishment of multifunctional training teaching system has changed fixed training contents and the previous teaching technology which just look at training results and ignore the phenomenon of the process of cultivating students' ability. Two Graduates of questionnaires shows multifunctional training teaching system not only can create ideal academic atmosphere, enhance students' professional and technical ability, but also can promote the cultivation of students' professional accomplishment and engineering thinking, so it is scientific and effective. The training is a very important part of the practical teaching, it still is not perfected right now and continues on exploring and practicing. There are still may have some issues to resolve in implementation process, such as students' consciousness of innovation and engineering thinking can't be consideration; teachers' abilities of production technology need a further enhance; the off-campus training bases are few and unstable; The hardware and software of the campus training bases can't keep up with social trends, etc. These questions rely on the research in the future and continuous improvement, and then make a set of comprehensive and improvement training teaching system.

\section{References}

[1] G.Q. Xi, F. Tan and F.M. Tian: Design and practice of comprehensive training teaching system of agricultural electrical engineering and information speciality, Journal of Science of Teachers' College and University, vol.33 (2013) p.91-93. (In Chinese)

[2] B.G. Sun, W.Y. Zhao, J.M. Wu and ZY. Cheng: Construct 311 systems and foster person with innovation ability in agricultural engineering, Chinese Agricultural Mechanization, No.1 (2009) p.91-92, 97,(In Chinese)

[3] J.H. Li and T. Zhao: Practice and study on the teaching reform of agricultural electrification and automation major, Chinese Agricultural Mechanization, No. 6 (2010) p.106-108, 112.(In Chinese)

[4] F. Jiang, C.L. Zhang, Y.J. Wang, Z.M. Xiao and C.G. Chen: The construction of training system for active practice ability of students in mechanical engineering major, Research in Higher Education of Engineering, No. 1 (2016) p.187-192.(In Chinese)

[5] S.F. Xiao, J.X. Chen, C.Y. Chen, Y. Xu and X. Zhang: Research and exploration in building the teaching system of traditional Chinese nursing train and west nursing train, Journal of Chinese Medicine, vol. 25 (2010) p.1224-1226.(In Chinese)

[6] L.L. Jiang, D. Peng, Y.S. Du and L.M. Chen: Research and practice on classified teaching mode in electrical and electronic technology experiment, Experimental Technology and Management, vol.33 (2016) p.201-204.(In Chinese) 